\title{
Tax Competition and Economic Geography
}

\author{
Fredrik Andersson ${ }^{* \dagger}$ and Rikard Forslid ${ }^{\ddagger \S}$
}

May 1999

\begin{abstract}
Tax competition between two countries is considered in a trade-and-location setting with differentiated products and monopolistic competition. There are two groups of workers, mobile ones and immobile ones. Taxes are used for producing a public good. It is shown that an equilibrium with mobile workers dispersed across countries is destabilised by increased taxes on these mobile workers - and this is shown to be true also for perfectly coordinated tax increases. It is also shown that an agglomeration is taxable, and that increasing public spending may relax the minimum tax pressure on immobile workers consistent with preserving an agglomeration.
\end{abstract}

JEL Classification: F12, F15, F21, R12

Keywords: agglomeration, economic geography, tax competition

\section{Introduction}

Regional agreements of economic integration such as EU and NAFTA aim at achieving free mobility of goods, people, capital, and services. There is a widespread recognition of the potential benefits of this in terms of higher allocation efficiency and increased competition. At the same time, however, local and national politicians, particularly in smaller regions, worry about the locational effects economic integration might have. In particular, there are widespread fears that locational competition by means of taxes will grow more fierce as economic integration proceeds. As a consequence it has been suggested that the next step must be harmonization of taxes.

The analysis of tax competition for mobile factors has a long tradition in economics. The point of departure for this literature is the coexistence of immobile and mobile factors of production in a group of politically sovereign jurisdictions, and the question to what extent public

\footnotetext{
${ }^{*}$ Correspondence to: Fredrik Andersson, Department of Economics, Lund University, P.O. Box 7082, S-220 07 Lund, Sweden. Phone +46-46-222 86 76, fax +46-46-222 46 13, email: Fredrik.Andersson@nek.lu.se.

${ }^{\dagger}$ Financial support from the Bank of Sweden Tercentenary Foundation is gratefully acknowledged.

${ }^{\ddagger}$ Lund University and CEPR; email: Rikard.Forslid@nek.lu.se.

${ }^{\S}$ Financial support from the Research Council of Norway (grant no.124559/510) and from the European Comission (TMR grant) is gratefully acknowledged.
} 
goods can be financed by means of taxes on mobile factors. A recurrent observation is that taxation of the mobile factor will be distorted downwards compared to a situation where all factors were immobile. The reason is the obvious externality that one jurisdiction's tax reduction exerts on other jurisdictions - tax revenue lost by others when mobile factors move are not internalised. This externality was observed by e.g. Oates (1972) and Gordon (1983), and aspects of the small-number case have been treated by e.g. Wildasin (1988) and de Crombrugghe and Tulkens (1990). The basic result that taxes are distorted downwards has been qualified along several lines; Wilson (1987) devises a model where symmetric jurisdictions end up charging different taxes and where this, in turn, leads to an inefficient distribution of public goods (and an inefficient pattern of trade); Persson and Tabellini (1992) show how tax competition may be mitigated in political equilibrium due to voters' strategically electing more tax-prone governments. Wildasin (1997) develops a model with risky human-capital investment in the presence of tax competition; he shows that labour market integration is unambiguously beneficial if the investments can be financed privately, whereas it is detrimental to immobile workers if it requires tax finance. The main focus of the tax competition literature is the taxation of mobile capital; this model, on the other hand, is tailored to address taxation of mobile labour. Whereas this is somewhat different, both constitute examples of taxation of mobile factors; the substantive difference between our paper and the tax competition literature is the way in which the goods space and the production are modelled.

A completely different strand of literature is the "new economic geography" literature, which analyses the relationship between trade integration and industrial location. In a series of seminal papers by Krugman (1991), Krugman and Venables (1995) and Venables (1996), it is shown how economic integration may lead to increased concentration of industrial production. This literature is based on the Spence-Dixit-Stiglitz framework of increasing returns to scale and monopolistic competition, together with trade costs. A key feature is that these models display hysteresis in location, meaning that once production has agglomerated in a region it tends to get stuck there because of demand and supply linkages. These linkages are an important explanation for the industrial clusters that can be observed in many real world regions such as the manufacturing belt of the US and the European "hot banana". A consequence of this is that mobile factors may not respond to marginal changes in tax rates if they are locked in by the existence of an industrial cluster. This stands in stark contrast to a standard neo-classical framework, where a marginal tax change in a region leads to a marginal movement of factors.

This paper uses the Forslid and Ottaviano (1999) version of the Krugman (1991) model to study the effect of taxes on the location of manufacturing production. The model is extended by including proportional taxes on the two categories of labour, and tax revenues are spent on country-specific public goods. Analysing tax competition in an economic-geography framework makes it possible to unveil forces absent in the traditional tax competition literature. First, the scope for taxation depends crucially on wether production is agglomerated or dispersed. The inertia introduced by agglomerative forces constitutes a fundamental reason for taxes not to 
be 'minimal' when the mobile factor is concentrated - location economies then produce taxable rents. (This force has been identified in somewhat different contexts by Ludema and Wooton (1998) and by Kind, Midelfart-Knarvik and Schjelderup (1998).) Second, the stability of an equilibrium where the mobile factor is dispersed may be affected by taxes. In particular taxes that redistribute between mobile and immobile factors can have dramatic effects on the location of production. In fact, it turns out that even perfectly coordinated tax increases on the mobile factor may destabilise a symmetric equilibrium. In contrast, tax changes that are uniform across factors only have gradual effects on the location of production. These observations have, as far as we know, not been made previously.

Few attempts have been made to date to address issues of tax competition in an economicgeography framework. An important exception is Ludema and Wooton (1998). In a framework with homogeneous-good oligopoly and moving costs (as opposed to the differentiated-product approach taken here), they focus on the effects of integration on the intensity of tax competition. They conclude that integration interpreted as decreasing trade costs, contrary to popular notions, attenuates tax competition; integration interpreted as increased labour mobility has mixed effects. One key conclusion of Ludema and Wooton is confirmed below; the inertia resulting from concentration of the mobile factor in one region gives, essentially, rise to a rent that is taxable. This latter conclusion is borne out also in Kind, Midelfart-Knarvik and Schjelderup (1998); more precisely they show that a country hosting an agglomeration may find it optimal to levy a source-based tax on capital income.

The paper is organised as follows. In Section 2, the model is developed and the stability properties of a symmetric equilibrium are related to the parameters of the model - in particular the effects of varying trade costs are considered. In Sections 3 and 4, taxes are introduced; the analysis first deals with the properties of 'symmetric' equilibria-i.e. equilibria where the mobile factor is dispersed - and then goes on to the properties of equilibria where the mobile factor is concentrated in one country. Section 5 is a conclusion.

\section{The Model}

This paper uses the Forslid and Ottaviano (1999) version of the Krugman (1991) model. Qualitatively the modified model behaves exactly like the original model but in addition it is analytically solvable. An additional attractive feature of the modified model is that the geographically mobile factor can be interpreted as skilled labour while unskilled labour is immobile. This makes the model more applicable in a European context. ${ }^{1}$ The model is extended by including proportional taxes on the two categories of labour, and tax revenues are spent on country-specific public goods.

\footnotetext{
${ }^{1}$ There is evidence that more highly educated labour is more mobile; see e.g. Pedersen (forthcoming).
} 


\section{$2.1 \quad$ Basics}

There are two countries, 1 and 2 (interchangeably referred to as regions), and two sectors. A homogeneous good is produced with a constant-returns technology using only unskilled labour, while differentiated manufactures are produced with increasing-returns technologies using both skilled and unskilled labour. Each region has $L^{U}$ unskilled workers which are geographically immobile. Skilled workers, amounting to $L_{W}^{S}$ worldwide, can migrate between countries. All individuals have the utility function

$$
U=C_{M}^{\mu} C_{A}^{1-\mu} G^{\gamma}
$$

where $\mu \in(0,1)$ and $\gamma>0$ are constants, $C_{A}$ is consumption of the homogenous good, and $G$ is the level of a public good produced in the region where the individual resides. Manufactures enter the utility function through the index $C_{M}$ which is defined by

$$
C_{M}=\left[\sum_{i=1}^{N} c_{i}^{(\sigma-1) / \sigma}\right]^{\sigma /(\sigma-1)}
$$

$N$ being the number of varieties consumed, $c_{i}$ being the amount of variety $i$ consumed, and $\sigma>1$ being the elasticity of substitution.

Each consumer spends a share $\mu$ of his income, $Y$, on manufactures, and demand for variety $i$ is

$$
x_{i}=\mu \cdot \frac{p_{i}^{-\sigma}}{\sum_{k=1}^{N} p_{k}^{1-\sigma}} \cdot Y .
$$

The unit factor requirement of the homogeneous good is one unit of unskilled labour. This good is freely traded, and since we also choose this good as numeraire we have $p_{A}=w^{U}=1$ ( $w^{U}$ being the wage of unskilled workers) in both countries.

In the production of differentiated goods, skilled workers only enter the fixed cost; this may be interpreted as the cost of $R \& D$ or headquarter services. The variable costs only consist of wages to unskilled workers. The world supply of skilled workers $L_{W}^{S}$ is constant so that $L_{1}^{S}+L_{2}^{S}=L_{W}^{S}$, where $L_{j}^{S}$ is the number of skilled workers in region $j$. The cost of producing $x_{i}$ units of manufactured commodity $i$ in region $j$ is

$$
\chi_{j}=\alpha w_{j}^{S}+\beta x_{i},
$$

where $w_{j}^{S}$ is the wage rate of skilled labour in region $j, \alpha$ is the fixed cost of skilled labour, and $\beta$ the requirement of unskilled labour per unit $x$. We will choose units of skilled labour so that $\alpha=1$. Trading the manufactured good involves a frictional trade cost of the "iceberg" form: in order for one unit of the good to arrive, $\tau>1$ units must be shipped.

Profit maximisation by firms, under the Chamberlinian large group assumption, leads to price

$$
p_{j}=\frac{\sigma}{\sigma-1} \beta
$$


of each differentiated commodity; choosing units of $x$ so that $\beta=(\sigma-1) / \sigma$ gives $p_{j}=1$. If there is free entry, the excess of variable revenue over variable cost must precisely cover the fixed cost (dropping superscript $S$ on mobile-worker wages),

$$
(1-\beta) x_{j}=w_{j}
$$

implying that

$$
x_{j}=\sigma w_{j}
$$

\subsection{Short-run equilibrium}

In the short run, the allocation of skilled workers is taken to be fixed. Full employment of this factor implies that the number of firms in region $j, n_{j}$, satisfies

$$
n_{1}=L_{1}^{S}, \quad n_{2}=L_{2}^{S}
$$

The model is closed by the M-sector market-clearing conditions, where the left-hand sides (supply) are derived from (7) and the right-hand sides follow from the demand functions in (3) exploiting that all varieties have producer price 1 ,

$$
\begin{gathered}
\sigma w_{1}=\frac{1}{n_{1}+\phi n_{2}} \mu Y_{1}+\frac{\phi}{\phi n_{1}+n_{2}} \mu Y_{2}, \\
\sigma w_{2}=\frac{\phi}{n_{1}+\phi n_{2}} \mu Y_{1}+\frac{1}{\phi n_{1}+n_{2}} \mu Y_{2} .
\end{gathered}
$$

The object $\phi=\tau^{1-\sigma}$, ranging between 0 and 1 , stands for "freeness" of trade (0 is autarchy and 1 is zero trade costs). Incomes are given by

$$
Y_{1}=L^{U}+w_{1} L_{1}^{S} ; \quad Y_{2}=L^{U}+w_{2} L_{2}^{S}
$$

Equations (8), (9), (10), and (11) determine the nominal wage in each region for given factor stocks. The endowment of skilled labour determines the size of the manufacturing sector and therefore also the fraction of unskilled labour that is allocated to manufacturing. The amount of unskilled labour in manufacturing equals $n \beta x$. Substituting $x$ and $n$ from (7) and (8) gives $n \beta x=(\sigma-1) w^{S} L^{S}$. We rule out corner solutions by assuming that $(\sigma-1) w^{S} L^{S}<L^{U}$, which ensures that the agricultural sector is active in both regions.

\section{$2.3 \quad$ Long-run equilibrium}

In the long run, the skilled workers are mobile between regions and responsive to the incentives provided by the relative utilities attainable in the two regions. The indirect utility of a worker is

$$
V_{j}=\left(\frac{\mu w_{j}}{P_{j}}\right)^{\mu} \cdot\left((1-\mu) w_{j}\right)^{1-\mu} \cdot G_{j}^{\gamma}=k w_{j} P_{j}^{-\mu} G_{j}^{\gamma}
$$


where $P_{j}$ is the ideal CES price index in region $j$,

$$
P_{1}=\left(n_{1}+\phi n_{2}\right)^{1 /(1-\sigma)}, \quad P_{2}=\left(\phi n_{1}+n_{2}\right)^{1 /(1-\sigma)} .
$$

We are going to focus on two kinds of equilibria. On the one hand, we will consider 'symmetric equilibria', or more generally 'dispersed equilibria'; i.e., equilibria where the mobile factor $i s$ not concentrated in one region. On the other hand we will deal with 'concentrated equilibria', or 'agglomerated equilibria'; i.e., equilibria where all manufacturing production is concentrated in one region.

\subsection{Stability}

Because of the symmetry of the two regions there always exists an equilibrium with $L_{1}^{S}=L_{2}^{S}=$ $L_{W}^{S} / 2$, and all other objects equal across regions. Consider first this symmetric equilibrium with public goods and taxes excluded from the analysis (formally: with $G$ removed from the utility function). In the case of free trade $(\phi=1)$ it is easy to check that real wages are always equal. This is no surprise since distance disappears from the model when trade costs are zero. Consequently the equilibrium allocation of workers is undetermined. When trade costs are infinite, $(\phi=0)$, the relative utility is given by

$$
\rho=\frac{w_{1} P_{1}^{-\mu}}{w_{2} P_{2}^{-\mu}}=\left(\frac{L_{1}}{L_{2}}\right)^{\frac{\mu}{\sigma-1}-1} .
$$

The symmetric equilibrium is stable if $\mu<\sigma-1$, which is assumed to hold. This condition corresponds to the "no-black-hole" condition in the original core-periphery model. ${ }^{2}$

The two special cases of free trade and prohibitive trade costs $(\phi=1$ and $\phi=0)$ can be analysed analytically in most location models. The more interesting case of intermediate trade costs is, however, not analytically tractable in standard models. Here, due to the simplicity of the demand functions in (9) and (10), we can solve the model analytically for general trade costs. This gives the relative real wage according to:

$$
\rho=\frac{w_{1} P_{1}^{-\mu}}{w_{2} P_{2}^{-\mu}}=\frac{-\lambda \mu\left(\phi^{2}-1\right)-\lambda \sigma(\phi-1)^{2}+(\mu+\sigma) \phi^{2}+\sigma-\mu}{\lambda \mu\left(\phi^{2}-1\right)+\lambda \sigma(\phi-1)^{2}+2 \sigma \phi}\left(\frac{\phi \lambda+1-\lambda}{\lambda+\phi(1-\lambda)}\right)^{\frac{\mu}{1-\sigma}},
$$

where $\lambda \equiv L_{1}^{S} /\left(L_{1}^{S}+L_{2}^{S}\right)$. Equation (15) expresses the relative real wage as a function of the state variable $\lambda$ and parameters of the model.

Two agglomeration forces are at work. On the demand-side, more skilled workers and firms in a region imply a larger market and therefore a more attractive place for additional firms and skilled workers to locate. On the supply-side, a larger region produces more varieties locally and therefore, with positive trade costs, has a lower price index. This implies a higher real wage,

${ }^{2}$ See Fuijita, Krugman and Venables (1999). 
Figure 1: Stability for Different Levels of Trade Costs

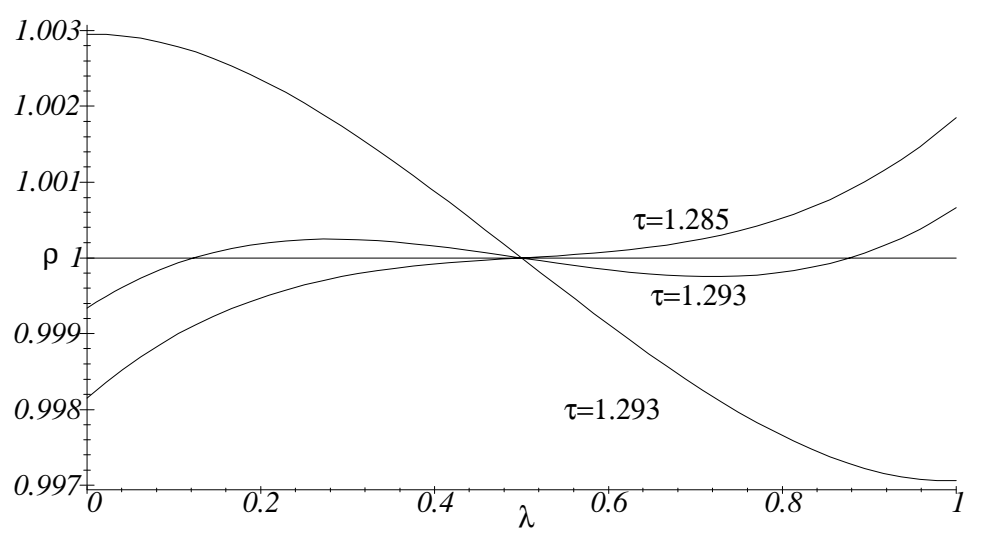

which attracts even more skilled labour and firms. In equation (15) this supply link can be seen as the last right-hand side parenthesis. Against the agglomeration forces stand trade costs as a dispersion force. Higher trade costs make it less attractive to serve markets via exports, which tends to disperse production.

Figure 1 plots relative utility (which, since public goods are absent, is simply relative real wages) as a function of the proportion of manufacturing workers residing in country $1, \lambda$, for different levels of trade costs. For high trade costs the symmetric equilibrium is stable, as the cost of supplying a market by exports is too large. For lower trade costs agglomerative forces come to dominate, which leads to a core-periphery outcome, and for intermediate trade cost the possibility of intermediate asymmetric equilibria appears. These equilibria are, however, unstable. This model, thus, behaves qualitatively exactly as the Krugman (1991) model. Figure 1 plots (15) for $\sigma=3, \mu=0.3$, and different levels of trade costs.

It is also straightforward to evaluate analytically the stability of different equilibria by differentiating (15) with respect to $\lambda$ and evaluating the derivative in the equilibrium of interest. The symmetric equilibrium $(\lambda=0.5)$ becomes unstable for trade costs lower than a certain "breakpoint"; in term of freeness, $\phi$, the breakpoint is given by:

$$
\phi^{\text {break }}=\frac{(\sigma-\mu)(\sigma-1-\mu)}{(\sigma+\mu)(\sigma+\mu-1)}
$$

The breakpoint is decreasing in $\mu$ and increasing in $\sigma$ by inspection. A larger expenditure share on manufacturing, $\mu$, increases agglomeration forces, which implies that the symmetric equilibrium is stable for a smaller range of trade costs. A larger $\sigma$ works in the opposite direction since it implies a lower mark-up in manufacturing and therefore lowers agglomeration forces. 
Next, we turn to the agglomerated equilibrium. The core-periphery equilibrium cannot be sustained for trade costs above the "sustainpoint", which - in terms of freeness - is given by:

$$
\phi^{\text {sust }}=\sqrt{\frac{\left(\sigma^{2}-\sigma-\mu(3 \sigma-1)\right)(\sigma-\mu)}{\left(\sigma^{2}-\sigma+\mu(3 \sigma-1)\right)(\sigma+\mu)}} .
$$

As in the Krugman (1991) model $\phi^{\text {sust }}<\phi^{\text {break }}$, which implies hysteresis in location. Once the core-periphery equilibrium is reached, trade costs have to rise above the breakpoint (which preserves the symmetric equilibrium) before the agglomerated equilibrium becomes unstable (compare figure 4 which plots stable equilibria against taxes). As $\mu$ goes towards zero the manufacturing sector disappears, and the breakpoint and sustainpoint both converge to one.

\section{Taxes-dispersed equilibrium}

We will assume that the two regions can impose proportional taxes, $t_{j}^{A}$ on unskilled-labour income and $t_{j}^{M}$ on skilled-labour income, initially taking taxes as fully exogenous. Note that since average taxes are the key determinant of the long-run equilibrium, this specification may be seen as shorthand for more general tax structures that are able to tax the two categories of workers differently. Furthermore, we will assume that there is an upper bound on the possibilities to tax immobile labour; in precise terms, we will assume that, $t_{j}^{A} \leq T^{A}$. This restriction has a natural interpretation as either a subsistence requirement, or as a proxy for some kind of political constraint.

We will assume that tax revenue is used to produce a region- $j$ public good, and to avoid intractable interactions, we will assume that the public good is produced by means of the average consumption basket; i.e., a fraction $1-\mu$ of the tax revenue is spent on agricultural goods, and a fraction $\mu$ on manufactures. An implication of this is that determination of short-run equilibrium is independent of taxes. The amount of the public good is equal to the expenditure (in numeraire units)

$$
G_{j}=t_{j}^{A} L^{U}+t_{j}^{M} w_{j} L_{j}^{S}
$$

Before we turn to the analysis we note that in order for skilled workers to stay in each of the regions, it must be true that the ratio between the indirect utilities of mobile workers in the two regions must be one. In formal terms (where we have factored out constants from the indirect utility function),

$$
\rho=\frac{w_{1} P_{1}^{-\mu}\left(1-t_{1}^{M}\right) G_{1}^{\gamma}}{w_{2} P_{2}^{-\mu}\left(1-t_{2}^{M}\right) G_{2}^{\gamma}}=1 .
$$

When performing various comparative statics exercises on a dispersed equilibrium-i.e., any equilibrium defined by (19) — it may seem that this relationship is necessarily upset. As will be shown, however, equilibrium is restored by migration of mobile labour. We will keep to the 
original model by assuming that workers myopically migrate to the more attractive region; as long as the stability of the dispersed equilibrium is preserved, migration of workers will thus restore equilibrium defined by (19) when taxes change. As will also be clear below, however, taxes may change the stability properties of a dispersed equilibrium.

\subsection{Stability and comparative statics of the dispersed equilibrium}

As we have noted, absent taxes there is always a symmetric equilibrium, and whenever trade costs are sufficiently high this equilibrium is stable. We will now explore how the symmetric equilibrium - and more generally any dispersed equilibrium - is affected by tax rates and the resulting amounts of public goods provided. The relative utility is obtained by substituting (18) into (19). Note that nominal wages do not depend on taxes since taxes do not enter equations (8), (9), (10), and (11). The effect of taxes can therefore be analysed separately from the determination of wages an price indices.

Taxes that are symmetric between factors but differ between countries Consider first the effect of taxes that differ between countries but are symmetric between sectors; $t_{1}^{M}=t_{1}^{A}=t_{1}$ and $t_{2}^{M}=t_{2}^{A}=t_{2}$. The relative utility of the two regions is now

$$
\rho=\frac{w_{1} P_{1}^{-\mu}\left(1-t_{1}\right) t_{1}^{\gamma}\left[L^{U}+\lambda L_{W}^{S} w_{1}\right]^{\gamma}}{w_{2} P_{2}^{-\mu}\left(1-t_{2}\right) t_{2}^{\gamma}\left[L^{U}+(1-\lambda) L_{W}^{S} w_{2}\right]^{\gamma}} .
$$

Since nominal wages do not depend on taxes, the effect of taxes can be analysed separately from wages and price indices in (20). Clearly the effect of taxes is bell-shaped in the sense that low taxes, on the one hand, imply a low provision of public goods which decreases the attractiveness of a location, whereas high taxes, on the other hand, imply a large decrease in disposable income which is again negative for utility. The welfare maximising tax is $t^{*}=\gamma /(1+\gamma)$, which increases with the importance of public goods in utility, $\gamma$.

Figure 2 shows a numerical example for $\tau=1.6, \sigma=4, \gamma=1$ and $\mu=0.3$. For these parameter values, taxes are below $t^{*}$ so country 1 attracts more workers as it increases taxes. The tax change, however, does not affect the slope of the relative indirect utility curve; as will be elaborated on below, this is due to the tax on mobile workers not changing relative to the tax on immobile workers. This type of general tax changes will, therefore, not cause catastrophical agglomeration. Rather, taxes that are uniform across factors will affect the level of manufacturing production in a country continuously. In fact, this case looks much like the standard result in a neoclassical model where a marginal change in taxation will have a marginal effect on location.

Taxes that redistribute between factors Next we assume that taxes are symmetric between countries but allow them to differ between sectors; $t_{1}^{M}=t_{2}^{M}=t^{M}, t_{1}^{A}=t_{2}^{A}=t^{A}$, but $t^{M} \neq t^{A}$. Taxes now redistribute between the two factors. The relative utility is given by 
Figure 2: Changes in the General Tax Level

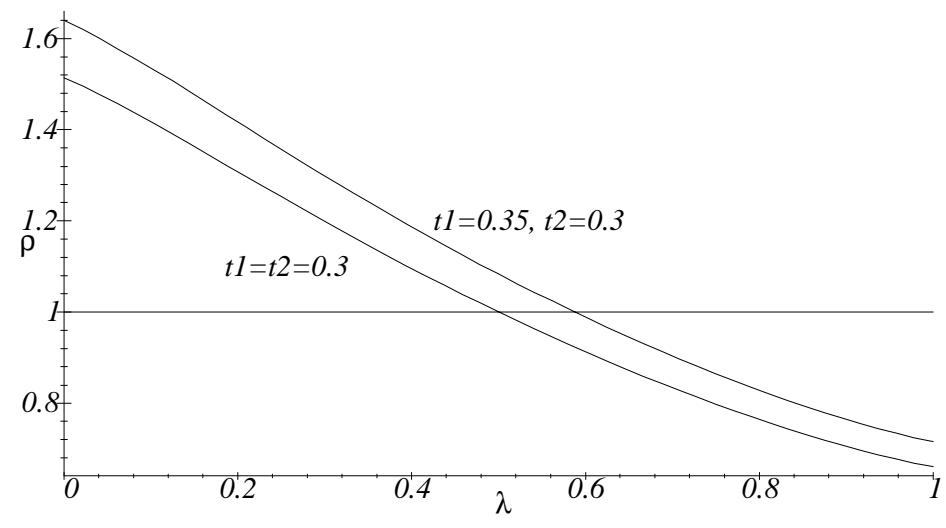

$$
\rho=\frac{w_{1} P_{1}^{-\mu}\left[L^{U} t^{A}+\lambda L_{W}^{S} w_{1} t^{M}\right]^{\gamma}}{w_{2} P_{2}^{-\mu}\left[L^{U} t^{A}+(1-\lambda) L_{W}^{S} w_{2} t^{M}\right]^{\gamma}} .
$$

Consider first a higher tax on mobile workers. As will be discussed below, the term $w_{j} L_{j}^{S}$ increases with immigration, this being one source of the potential instability of a dispersed equilibrium. A higher $t^{M}$ magnifies the effect of the term $w_{j} L_{j}^{S}$, and this is the reason for high taxes on mobile labour to destabilise a dispersed equilibrium. A higher $t^{A}$, on the contrary, decreases the relative importance of tax revenues from skilled workers and stabilises the equilibrium. The intuition is that the "technology" of public-good provision adds an additional agglomerative force to the model; this through the economies - essentially an instance of scale economies - of a larger population sharing the cost of a given level of provision of the public good. The strength of this force at a dispersed equilibrium depends on the amount of public good that is financed from mobile-labour income; the higher are taxes on mobile labour-and consequently the more of the public good is provided - the stronger is the reason to reside in a more populous region.

Figure 3 provides a numerical example for $\sigma=4, \mu=0.3, \gamma=1$, and $\tau=1.35$. Taxes on unskilled workers are held at 0.3 while taxes on skilled workers are changed symmetrically in both countries.

Tax changes can thus have dramatic effects on the location of manufacturing. Comparing with Figure 1, a higher tax on skilled workers has qualitatively the same effect as trade liberalisation - it rotates the relative indirect utility anti-clockwise. As taxes on skilled labour are set above a critical value - the "breakpoint" - the symmetric equilibrium ceases to be stable. 
Figure 3: Redistributing Taxes

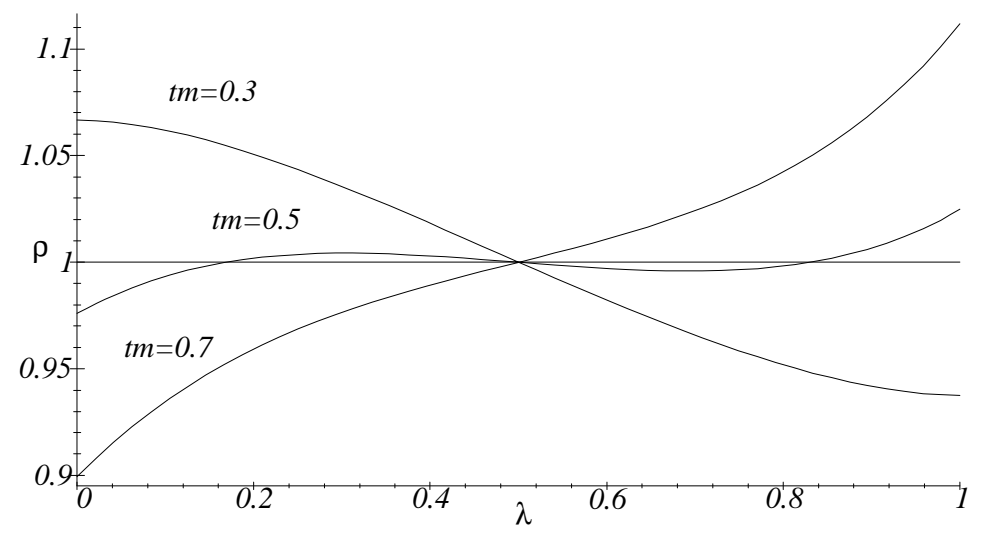

Figure 4: Stable long run equilibria

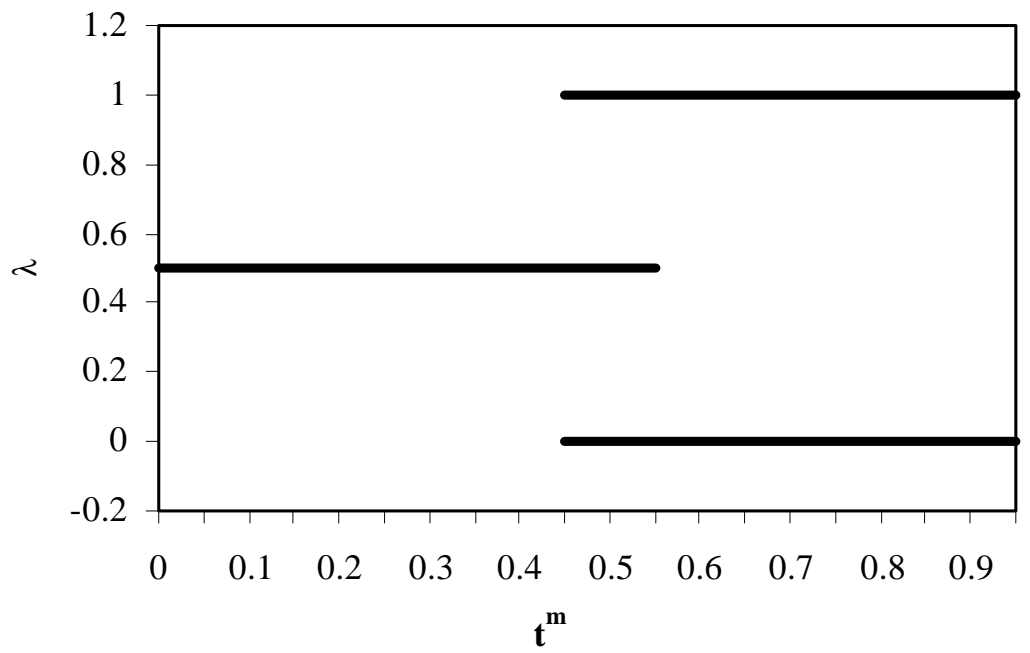


For a country worrying about loss of manufacturing as a consequence of economic integration, taxes become imperative. A tax that redistributes from immobile factors to mobile factors will counteract the effects of economic integration. Put differently, if countries integrate economically harmonization of taxes may not suffice to preserve the location of industry. Harmonization and lowering of taxes on skilled workers (or increasing taxes on unskilled workers) may be necessary.

Figure 4 shows the configuration of long-run equilibria for different tax levels on skilled workers. The symmetric equilibrium $(\lambda=0.5)$ ceases to be stable as taxes are increased above the "breakpoint," at which a bifurcation occurs. At this point all manufacturing (and skilled workers) agglomerate in one of the regions. The figure illustrates the important feature of this type of model that it displays hysteresis in location: Once the tax rate is moved marginally above the breakpoint and a core-periphery structure is established, it is not enough to lower taxes back to its previous level to re-establish a symmetric equilibrium; taxes have to be lowered well below the breakpoint (to the "sustainpoint") before a symmetric equilibrium again becomes stable and the core-periphery structure ceases to be stable.

General tax changes - stability We will start the general analysis by considering the stability properties of the case with general taxes: $t_{1}^{M}, t_{1}^{A}, t_{2}^{M}, t_{2}^{A}$. As is indicated by figures 2 and 3 , the impact of taxes on the stability of a dispersed equilibrium depends on the relationship between taxes on mobile labour and taxes on immobile labour. The direction of this effect turns out to hinge on the fact that skilled-labour income, $w_{j} L_{j}^{S}$, increases as more skilled workers move to a region; this can be shown by solving the model. ${ }^{3}$ Due to this fact-total mobile-labour wages increasing with the number of mobile workers - a dispersed equilibrium is destabilised by taxes on mobile workers; this is shown in the Appendix. Furthermore, it can be shown that the extent to which a dispersed equilibrium is destabilised depends on taxes through the ratios $t_{j}^{M} / t_{j}^{A}$ in the respective regions, and that it depends positively on each of them; the argument can found in the Appendix. This property was reflected above - taxes that were symmetric between factors turned out not to affect stability, while redistributive taxes turned out to do so.

General tax changes - comparative statics Consider next the general comparative statics of a dispersed equilibrium. As is indicated by figure 2, the comparative statics of the share of high-skilled workers in region $1, \lambda$, as a function of taxes has the natural property that - at a stable equilibrium - making region 1 more attractive to high-skilled workers leads to immigration. This may be seen formally by noting that, by implicit differentiation of (19), for $z=A, M$,

$$
\frac{d \lambda}{d t_{1}^{z}}=-\frac{\partial \rho / \partial t_{1}^{z}}{\partial \rho / \partial \lambda}
$$

Since $\partial \rho / \partial \lambda<0$ at a stable equilibrium, a tax change will lead to immigration precisely if $\rho$ increases; that is, precisely if the relative indirect utility of a high-skilled worker increases in

\footnotetext{
${ }^{3}$ Evaluated at the symmetric equilibrium $d w L^{S} / d \lambda=8 \phi \sigma \mu L u /\left[(\sigma-\mu)\left((\sigma+\mu) \phi^{2}+2 \sigma \phi+\sigma-\mu\right)\right]>0$, where $\lambda$ is the proportion of mobile workers residing in country 1 .
} 
region 1. Similarly, any change in region-2 taxes that makes region 2 less attractive for mobile workers will lead to immigration in country 1 . Obviously, a completely symmetric argument applies to country 2 .

Finally, consider the actual impact of tax changes in the general case of (19) with no constraint on the pattern of taxes. Taxes introduce a factor

$$
\eta_{1}=\left(1-t_{1}^{M}\right)\left[L^{U} t_{1}^{A}+\lambda L_{W}^{S} w_{1} t_{1}^{M}\right]^{\gamma}
$$

multiplying the real wage in country 1 , and a similar factor for country 2 . Since

$$
\frac{\partial \eta_{1}}{\partial t_{1}^{A}}=\left(1-t_{1}^{M}\right) L^{U} \gamma\left[L^{U} t_{1}^{A}+\lambda L_{W}^{S} w_{1} t_{1}^{M}\right]^{\gamma-1}>0
$$

high taxes on immobile workers are always conducive to keeping mobile workers. Hence, if country 1 has such an objective, it will set $t_{1}^{A}=T^{A}$. The effect of higher $t_{1}^{M}$ is given by

$$
\frac{\partial \eta_{1}}{\partial t_{1}^{M}}=\left(\frac{\left(1-t_{1}^{M}\right) \lambda L_{W}^{S} w_{1} \gamma}{L^{U} t_{1}^{A}+\lambda L_{W}^{S} w_{1} t_{1}^{M}}-1\right)\left[L^{U} t_{1}^{A}+\lambda L_{W}^{S} w_{1} t_{1}^{M}\right]^{\gamma}
$$

and country 1 will wish to increase it as long as this expression is positive. Expression (25) is decreasing in $t_{1}^{M}$, and it is positive at $t_{1}^{M}=0$ provided that

$$
\lambda L_{W}^{S} w_{1} \gamma>L^{U} t_{1}^{A}
$$

that is, provided that the income of high-skilled workers in region 1 weighted by the importance of the public good in utility is large enough relative to the tax revenue from immobile workers. If (26) is satisfied, (25) is zero at

$$
t_{1}^{M}=\frac{\lambda L_{W}^{S} w_{1} \gamma-L^{U} t_{1}^{A}}{\lambda L_{W}^{S} w_{1}(1+\gamma)} .
$$

A country wishing to attract mobile workers will increase $t_{1}^{M}$ to the point where $\eta_{1}$ is no longer increasing. Provided that $(26)$ is satisfied at $t_{1}^{A}=T^{A}$, it is thus optimal-from a strictly locational point of view - to tax the mobile workers at a positive rate. The intuition for this result is that the tax revenues from unskilled workers do not result in a high enough provision of public goods, and therefore skilled workers prefer a positive tax rate.

Discussion If politicians only care about the level of manufacturing production the analysis above leads to the following conclusions: When taxes are spent on public goods, it may be optimal for a country - even if it is considering only locational aspects - to tax the mobile factor at a positive rate. Indeed, a higher general tax rate can lead to more industry if tax rates are initially low; even if taxes are high, however, an increasing general tax rate (i.e., a tax rate uniform across sectors) leads to a gradual loss of industry rather than a catastrophical agglomeration.

The question of distribution of taxes between mobile and immobile workers, on the contrary, becomes critical. Although a positive tax on the mobile factor may serve to make a location 
more attractive when the maximal tax revenues from the immobile factor are insufficient, it is nevertheless true that a tax increase on mobile workers will destabilise a dispersed equilibrium. The important point is that redistributive taxes affect the agglomerative forces, and they can therefore have dramatic effects on the equilibrium configuration of industry. A higher tax rate on mobile workers destabilises the symmetric equilibrium and may lead to a dramatic loss of industry due to self-reinforcing agglomeration forces. Importantly, this will be the case even if the high taxes on skilled workers are harmonized between countries.

\subsection{Political equilibrium}

Let us contemplate the above results in the light of competition between two countries for mobile workers. Since workers move mechanically towards the country with a higher indirect utility, it is clear that any situation where a country does not maximize the indirect utility of its mobile workers cannot be an equilibrium: The country in question could improve the situation of the mobile workers presently residing there and at the same time create an inflow of workers.

Thus, a political equilibrium must be a situation where each country maximizes

$$
V_{j}=k w_{j} P_{j}^{-\mu}\left(1-t_{j}^{M}\right)\left[L^{U} t_{j}^{A}+L_{j}^{S} w_{j} t_{j}^{M}\right]^{\gamma}
$$

subject to the subsistence constraint for immobile workers. As we have seen above, this solution entails the subsistence constraint being binding, $t_{j}^{A}=T^{A}$. We have also seen that the optimal tax rate on mobile workers is strictly positive if condition (26) is satisfied at $t_{j}^{A}=T^{A}$.

If the countries are fully symmetric, this shows the existence of a fully symmetric political equilibrium; i.e., an equilibrium with $\lambda=1 / 2, w_{1}=w_{2}$, and with taxes satisfying $t_{1}^{A}=t_{2}^{A}=T^{A}$ and $t_{1}^{M}=t_{2}^{M}=t^{M *}, t^{M *}$ being the solution to (27) if condition (26) is satisfied at $t_{j}^{A}=T^{A}$, and zero otherwise.

This conclusion must be qualified if "political-equilibrium taxes"-i.e., taxes maximising (28) - are so high that the symmetric equilibrium is destabilised (cf. figure 3). Since we do not model the dynamics of the break-down of a dispersed equilibrium, we cannot make definitive statements about "transition values" of parameters with respect to the two kinds of equilibria. It seems clear, however, that the symmetric equilibrium will break down when it is unstable at taxes maximisng $V_{j}$ in (28) - it is not in the interest of any country to reduce taxes on mobile workers below this level unilaterally since that country seems to be the likely loser in the contest for hosting the agglomeration. Thus, once trade-costs are low enough to undermine the symmetric equilibrium at political-equilibrium tax rates, agglomeration seems to be the likely outcome.

The emergent conclusions are that whereas the notion that immobile factors are likely to be taxed very heavily due to competition for mobile workers is supported, the notion that this leads to very low taxes for mobile workers themselves is not.

Welfare aspects The welfare consequences of the above results are extremely clear-cut, albeit quite important. In short, if the objective is to attract mobile workers and the activities coming 
with mobile labour, the political equilibrium is one where the welfare of mobile workers is maximized subject to a feasibility constraint derived from the extent to which immobile labour can be taxed. This outcome is, obviously, unlikely to coincide with an unconstrained welfare optimum. One should notice, however, that the situation considered-viz. one where workers are costlessly mobile and where their utilities are equalised across countries - is a very competitive one; as will be clear below, the inertia implied by agglomeration is a mitigating factor.

\section{Taxes-agglomerated equilibrium}

Whenever trade costs are small enough, there is an equilibrium where one country is the host of all manufacturing. Consider a situation where all manufacturing is concentrated in country

1. The sales of a firm in this region is given by

$$
R_{1}=\frac{\mu}{N}\left(Y_{1}+Y_{2}\right)
$$

where $N$ denotes the total number of manufacturing firms in the world. The sales of the first firm that moves to region 2 is

$$
R_{2}=\frac{\mu}{N}\left(\phi Y_{1}+\phi^{-1} Y_{2}\right)
$$

In order to attract workers to region 2 the firms must pay

$$
w_{2}=\tau^{-\mu} \frac{\left(1-t_{1}^{M}\right) G_{1}^{\gamma}}{\left(1-t_{2}^{M}\right) G_{2}^{\gamma}} w_{1}
$$

where $w_{1}=2 \mu L^{U} /(\sigma-\mu) L_{W}^{S}$ from equations (8), (9), (10), and (11). If the ratio of sales (profits) is larger than the ratio of costs the firm will defect from region 1 . The condition for this to happen is given by:

$$
\nu=\tau^{-\mu}\left[\tau^{(1-\sigma)} \frac{\sigma+\mu}{2 \sigma}+\tau^{(\sigma-1)} \frac{\sigma-\mu}{2 \sigma}\right] \frac{\left(1-t_{2}^{M}\right) G_{2}^{\gamma}}{\left(1-t_{1}^{M}\right) G_{1}^{\gamma}}>1 .
$$

A condition for an established agglomeration to be stable is therefore $\nu \leq 1$. The expression can be decomposed into two factors - one depending on trade costs and the other parameters of the model, and one depending on taxes - each with the property that increasing it makes concentration in country 1 less likely.

Consider first the factor associated with trade costs:

$$
\eta=\tau^{-\mu}\left[\tau^{(1-\sigma)} \frac{\sigma+\mu}{2 \sigma}+\tau^{(\sigma-1)} \frac{\sigma-\mu}{2 \sigma}\right]
$$

This term is non-monotonic in trade costs as shown in Figure 5, which plots $\eta$ for $\sigma=4$ and $\mu=0.3$.

For a large range of trade costs the scope for taxation of the mobile factor is increasing with trade integration (falling trade costs) reaching a maximum at the bottom of the U-curve 
Figure 5: Effect of trade costs

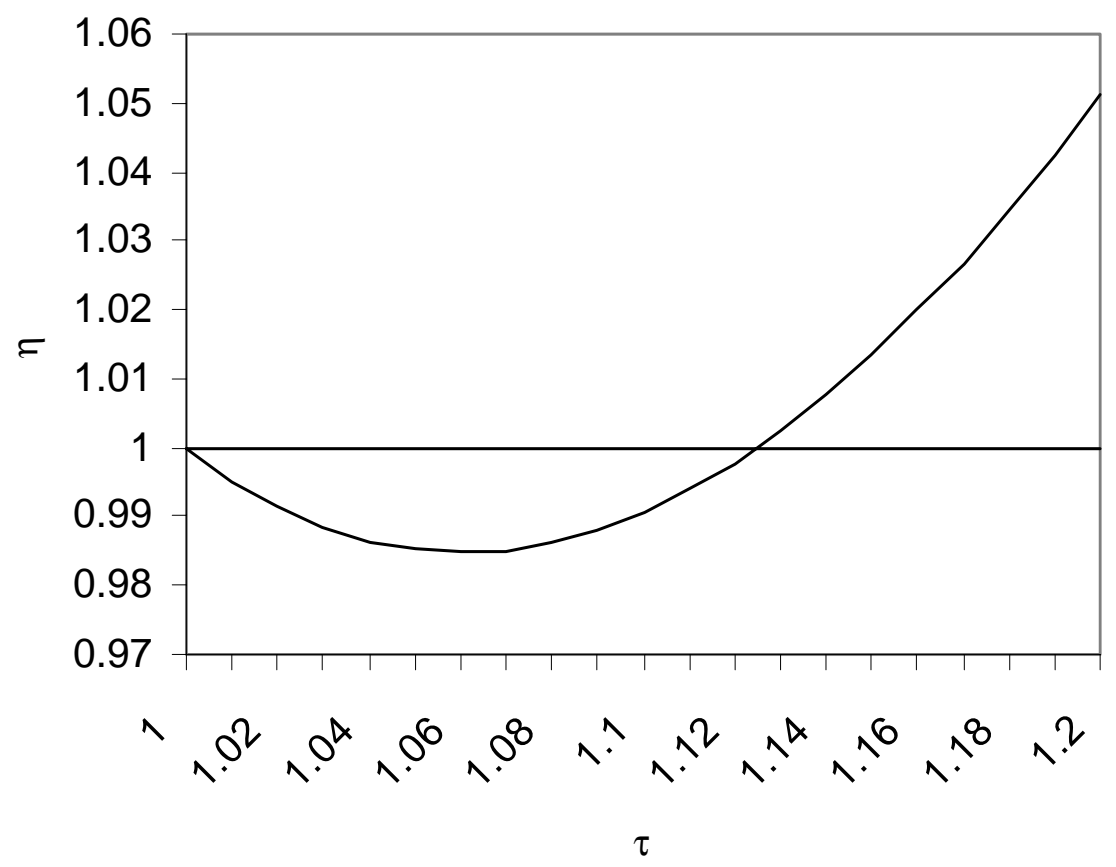

in Figure 5. (This result can also be found in Kind et al. (1998).) Interestingly the relation between taxes and trade costs are exactly the opposite in the case with dispersed production, where lower trade costs decreases the scope for taxation of skilled labour. For very low trade costs (the downward sloping segment in Figure 5), however, trade liberalisation again decreases the scope for taxation of the mobile factor.

Next consider the factor depending on taxes; because of concentration,

$$
G_{1}=t_{1}^{A} L^{U}+t_{1}^{M} w_{1} L^{S}=t_{1}^{A} L^{U}+t_{1}^{M} \frac{2 \mu L^{U}}{(\sigma-\mu)}, \text { and } G_{2}=t_{2}^{A} L^{U}
$$

and inserting this into (32), we have the following factor - the last factor of (32),

$$
\theta=\frac{\left(1-t_{2}^{M}\right)\left(t_{2}^{A} L^{U}\right)^{\gamma}}{\left(1-t_{1}^{M}\right)\left(t_{1}^{A} L^{U}+t_{1}^{M} 2 \mu L^{U} /(\sigma-\mu)\right)^{\gamma}}=\frac{\left(1-t_{2}^{M}\right)\left(t_{2}^{A}\right)^{\gamma}}{\left(1-t_{1}^{M}\right)\left(t_{1}^{A}+t_{1}^{M} 2 \mu /(\sigma-\mu)\right)^{\gamma}},
$$

(again with the property that increasing it makes concentration in country 1 less likely). Considering combinations of taxes that keep $\theta$ constant at $\theta_{0}$, we can solve for $t_{1}^{A}$, getting,

$$
t_{1}^{A}=\left(\frac{\left(1-t_{2}^{M}\right)}{\theta_{0}\left(1-t_{1}^{M}\right)}\right)^{1 / \gamma} t_{2}^{A}-\frac{2 \mu}{(\sigma-\mu)} t_{1}^{M} .
$$

This expression shows combinations of tax rates that "keep agglomerative forces constant"; e.g., if $\theta_{0}$ is chosen in such a way that $\nu$ in (32) is equal to one, it shows the lowest tax on immobile labour - the lowest $t_{1}^{A}$ - that is consistent with agglomeration in country 1 . 
Figure 6: Taxes consistent with agglomeration

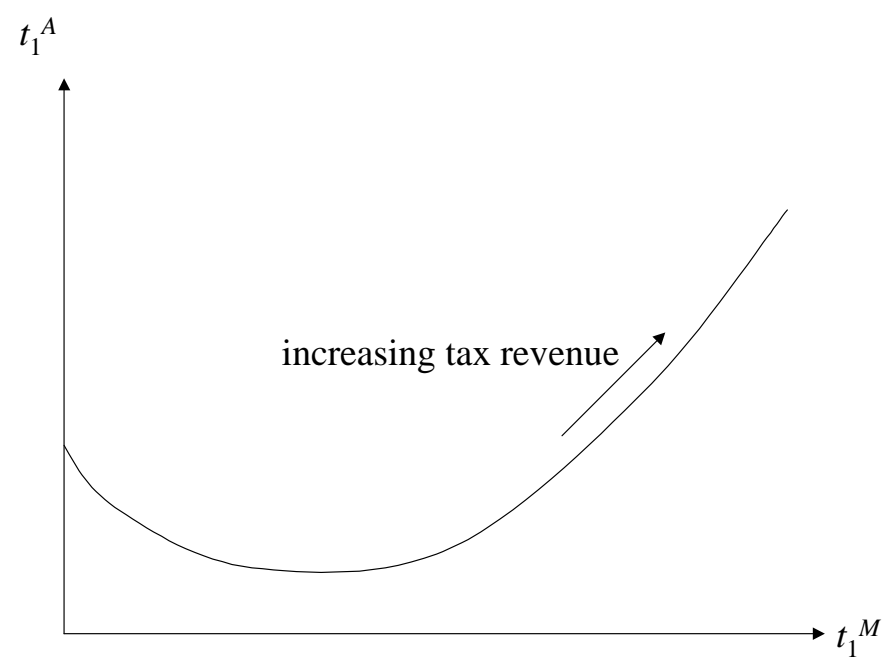

A higher tax rate on lowskilled workers makes a location more attractive for the mobile skilled workers, since it implies a higher provision of public goods. Therefore if region 2 increases its tax rate on lowskilled worker's income so must region 1 to maintain the relative attractiveness of region 1 for skilled workers. Further, a higher tax on skilled worker's income in region 2 makes this region unambiguously less attractive; the small mass of workers that moves to region 2 get a negligible share of the public goods paid by the tax. A tax on region-1 skilled worker's income has two opposing effects on the attractiveness of a region; it decreases disposable income of skilled workers, but it also increases the provision of public goods. These two effects are reflected by the two RHS terms in equation (36). For very high tax rates the first term will always dominate implying that higher taxes on skilled labour makes the location less attractive. For low tax rates, however, it is possible that the second term dominates so that the increased provision of public goods associated with higher taxes makes the location more attractive. Figure 6 shows the lowest tax on low-skilled workers compatible with agglomeration in country 1 as a function of the tax on high-skilled workers in such a case.

Thus, the insight that an agglomeration constitutes a somewhat immobile tax base is borne out in this context as well. The potential for the set of feasible taxes to be U-shaped as indicated in Figure 6 has an interpretation: As one moves along the curve, the amount of public goods increases. ${ }^{4}$ This means that the public sector is minimal at $t_{1}^{M}=0$; this, however, is not the point where the tax on low-skilled workers is minimal. Hence, there is not a trade-off between

\footnotetext{
${ }^{4}$ This is obvious: as one moves to the right, $t_{1}^{M}$ increases and the utility of high-skilled workers is held constant; thus public-good provision must increase.
} 
protecting an immobile tax base from heavy taxation and sustaining public expenditures in this region. Although this is merely a possibility, and although it is true only for small taxes, it is an important qualification of the widespread notion that this is an unavoidable trade-off. ${ }^{5}$

One may note that the subsistence constraint for immobile workers, $t_{j}^{A} \leq T^{A}$-which turned out to be binding in political equilibrium in tax competition when manufacturing was dispersed - need not be binding in any one of the countries in political equilibrium in tax competition when manufacturing is concentrated. Taxes consistent with the host country keeping the agglomeration were described above; for the other country, maximizing the welfare for the remaining - immobile - workers seems to be the obvious goal, and this is likely to involve less than maximal taxes. In this sense, the agglomerated case is thus somewhat less competitive.

\subsection{Comparing the symmetric and the agglomerated case}

Perhaps the most salient feature of the analysis is that the natural inverted U-shape of utility as a function of taxes when taxes are used to finance public goods "survives" tax competition, both in a dispersed equilibrium and in an agglomerated equilibrium. This is true in the sense that there are forces tending to keep tax rates positive also on mobile labour in both kinds of equilibria - although the strength of these forces are moderated by tax competition. Another important feature of the analysis is that taxes on mobile labour in addition to repelling mobile labour also destabilise dispersed equilibria.

A noteworthy difference between the symmetric and the agglomerated equilibria is that the relation between trade liberalisation and the scope for taxes on mobile factors are exactly reverse in the two equilibria for a large range of trade costs (the segment with positive slope in Figure 5). Another way to put this is that, in this model, it matters with whom a region or country is integrating. A highly industrialised country, caring about its industrial base, would gain more tax independence as trade is liberalized with a developing country, since the reason for tariff-jumping into the developing country is diminished. ${ }^{6}$ If the same country liberalises trade against another highly industrialised country, however, the result is stronger competition for mobile skilled workers. This gives less scope for independent taxation.

\section{Conclusion}

This paper analyses the effect of taxes and public goods on the location of mobile factors using a "new economic geography" model. In these models firms face pecuniary externalities in large markets, which creates agglomerative forces as well as hysteresis in location. The paper contains several conclusions. Changes in the overall tax level have locational effects quite similar to those

\footnotetext{
${ }^{5}$ Granted, when taking aspects such as the content of public expenditures into account, the likelihood of a downward-sloping part of the curve may be smaller still.

${ }^{6}$ Of course other reasons to relocate, such as abundance of cheap low skilled workers, does not enter this model.
} 
in the standard tax competition literature, where tax changes give gradual effects on location of mobile factors. Taxes that affect the distribution between mobile and immobile factors, however, can have dramatic effects since they affect the agglomerative forces. A small redistribution from mobile workers to immobile workers may render an equilibrium with mobile labour dispersed unstable, and cause a catastrophical agglomeration where all manufacturing production and all skilled workers end up in one country. Notably, this effect can result from a tax increase that is perfectly coordinated across countries - the instability originates in high tax levels on mobile workers per se, not from different taxes across countries.

From the trade and location literature it is well known that trade liberalization may trigger agglomeration. As illustrated in this paper this outcome may be avoided - or at least suspended - by changing taxes so as to redistribute from the immobile factor to the mobile factor. In the face of economic integration thus, shifting of the tax burden from mobile labour to immobile labour may be an effective means to halt concentration of the mobile workers.

Another conclusion that follows from the analysis is that an agglomeration, once established, produces rents that are taxable, and that taxes are not generally driven down to some minimum in the country hosting an agglomeration. This observation has been made previously by Kind et al. (1998) and by Ludema and Wooton (1998). Moreover, our model points to the possibility that for some tax levels, there is not a trade-off between protecting immobile workers from excessive taxation and sustaining a certain level of public-good provision - the minimal tax on immobile workers consistent with keeping the agglomeration of mobile workers is not necessarily everywhere increasing in the amount of public goods provided.

Finally, comparing the two types of equilibria, the relation between trade liberalisation and the scope for taxation of the mobile factor are reversed in the agglomerated and the symmetric equilibria. When liberalising against a country without manufacturing industry the scope for taxation actually increases, since the tariff-jumping argument for production in the other region becomes less important. On the contrary, when trade barriers are lowered between two regions with manufacturing agglomerations the competition for manufacturing is increased. Essentially, agglomeration forces become more dominant as trade costs are lowered. This increases the possibility that one region becomes dominant, so that the symmetric equilibrium breaks down and all manufacturing industry and skilled workers end up in one region. 


\section{Appendix}

The stability of symmetric equilibrium with general taxes Denote the relative real wage $\omega=w_{1} P_{1}^{-\mu} / w_{2} P_{2}^{-\mu}$ and let the component introduced by taxes be denoted $\theta$. Relative indirect utility is then $\rho=\omega \cdot \theta$, with

$$
\theta=\frac{\left(1-t_{1}^{M}\right)\left[L^{U} t_{1}^{A}+\lambda L_{W}^{S} w_{1} t_{1}^{M}\right]^{\gamma}}{\left(1-t_{2}^{M}\right)\left[L^{U} t_{2}^{A}+(1-\lambda) L_{W}^{S} w_{2} t_{2}^{M}\right]^{\gamma}}
$$

Stability is determined by the derivative of $\rho$ with respect to $\lambda$ at the symmetric equilibrium, and this derivative is

$$
\frac{d \rho}{d \lambda}=\frac{d \omega}{d \lambda} \cdot \theta+\omega \cdot \frac{d \theta}{d \lambda}
$$

Since real wages are independent of taxes, $d \omega / d \lambda$ is precisely the slope $\rho$ absent taxes. The effect of taxes thus depends on:

$$
\begin{gathered}
\frac{d \theta}{d \lambda}=\theta \cdot\left(\frac{\left(1-t_{1}^{M}\right) \gamma\left[L^{U} t_{1}^{A}+\lambda L_{W}^{S} w_{1} t_{1}^{M}\right]^{\gamma-1} t_{1}^{M}}{\left(1-t_{1}^{M}\right)\left[L^{U} t_{1}^{A}+\lambda L_{W}^{S} w_{1} t_{1}^{M}\right]^{\gamma}} \cdot \frac{d\left(\lambda L_{W}^{S} w_{1}\right)}{d \lambda}-\right. \\
\left.\frac{\left(1-t_{2}^{M}\right) \gamma\left[L^{U} t_{2}^{A}+(1-\lambda) L_{W}^{S} w_{2} t_{2}^{M}\right]^{\gamma-1} t_{2}^{M}}{\left(1-t_{2}^{M}\right)\left[L^{U} t_{2}^{A}+(1-\lambda) L_{W}^{S} w_{2} t_{2}^{M}\right]^{\gamma}} \cdot \frac{d\left((1-\lambda) L_{W}^{S} w_{2}\right)}{d \lambda}\right)
\end{gathered}
$$

since $d\left(\lambda L_{W}^{S} w_{1}\right) / d \lambda$ is positive (which can be verified by solving the model as noted in the text), and thus $d\left((1-\lambda) L_{W}^{S} w_{2}\right) / d \lambda$ negative, $d \theta / d \lambda$ is unambiguously positive. The introduction of public goods and taxes thus destabilises the symmetric equilibrium. The magnitude of this effect depends on taxes, but the derivatives $d\left(\lambda L_{W}^{S} w_{1}\right) / d \lambda$ and $d\left((1-\lambda) L_{W}^{S} w_{2}\right) / d \lambda$ do not since short-run equilibrium is independent of taxes. The magnitude of the effect thus only depends on taxes as far as is explicit in the above expression for $d \theta / d \lambda$; simplifying this expression, we get

$$
\frac{d \theta}{d \lambda}=\theta \gamma\left(\frac{1}{L^{U} t_{1}^{A} / t_{1}^{M}+\lambda L_{W}^{S} w_{1}} \frac{d\left(\lambda L_{W}^{S} w_{1}\right)}{d \lambda}-\frac{1}{L^{U} t_{2}^{A} / t_{2}^{M}+(1-\lambda) L_{W}^{S} w_{2}} \frac{d\left((1-\lambda) L_{W}^{S} w_{2}\right)}{d \lambda}\right),
$$

showing that any country increasing the relative tax burden on mobile workers (measured by $\left.t_{j}^{M} / t_{j}^{A}\right)$ destabilises the symmetric equilibrium. Moreover - noting that the second term of (A.2) "begins with" $\omega \cdot \theta$ which is equal to one in any dispersed equilibrium - this is the full effect. 


\section{References}

de Crombrugghe, A. and H. Tulkens, 1990. On Pareto improving commodity tax changes under fiscal competition. Journal of Public Economics 41: 335-50.

Dixit, A. and J. Stiglitz, 1977. Monopolistic competition and optimum product diversity. American Economic Review 67: 297-308.

Forslid, R. and G. Ottaviano, 1999. Trade and agglomeration: An analytically solvable case. Mimeo, Lund University.

Fujita, M., P. Krugman and A.J.Venables, 1998. The Spatial Economy: Cities, Regions and International Trade. Manuscript.

Gordon, R., 1983. An optimal tax approach to fiscal federalism. Quarterly Journal of Economics: 98 : 567-86.

Kind, H., K. H. Midelfart Knarvik, and G. Schjelderup, 1998. Industrial agglomeration and capital taxation. Discussion Paper 7/98, Department of Economics, Norwegian School of Economics and Business Administration.

Krugman, P., 1991. Increasing returns and economic geography. Journal of Political Economy 99:483-99.

Krugman, P. R. and A. J.Venables, 1995. Globalization and the inequality of nations. Quarterly Journal of Economics 60: 857-80.

Ludema, R. and I. Wooton, 1998. Economic geography and the fiscal effects of regional integration. CEPR Discussion Paper No. 1822.

Oates, W., 1972. Fiscal Federalism. New York, Harcourt Brace Jovanovich.

Pedersen, P., forthcoming. Scandinavian Skill Migration in Perspective of the European Integration Process. North-Holland, Amsterdam.

Persson, T., and G. Tabellini, 1992. The politics of 1992: Fiscal policy and European integration. Review of Economic Studies 59: 689-701.

Venables, A. J., 1996. Equilibrium Location of Vertically Linked Industries. International Economic Review 37: 341-59.

Wildasin, D., 1988. Nash equilibria in models of fiscal competition. Journal of Public Economics 35: $229-40$.

Wildasin, D., 1997. Labour market integration, investment in risky human capital, and fiscal competition. Mimeo, Vanderbilt University.

Wilson, J., 1987. Trade, capital mobility, and tax competition. Journal of Political Economy 95: 835-56. 